\title{
Mitochondrial and microsatellite DNA analyses showed comparative genetic diversity between parent and offspring populations of Korean black rockfish in a hatchery facility
}

\author{
H.S. An, J.W. Lee, J.Y. Park, J.I. Myeong and C.M. An \\ Biotechnology Research Division, \\ National Fisheries Research and Development Institute, Busan, Korea \\ Corresponding author: H.S. An \\ E-mail: hsan97@korea.kr
}

Genet. Mol. Res. 12 (4): 6389-6401 (2013)

Received June 17, 2013

Accepted October 1, 2013

Published December 9, 2013

DOI http://dx.doi.org/10.4238/2013.December.9.2

\begin{abstract}
The black rockfish, Sebastes inermis (Sebastidae), is an important commercial fishery resource in Korea. As a preliminary investigation into the effect of artificial reproduction in a hatchery facility, the genetic divergence between parent and offspring populations of black rockfish was accessed using 10 polymorphic nuclear microsatellite DNA loci and a mitochondrial (mt) control gene. All loci that were screened showed marked polymorphisms. mtDNA control region sequences were also highly variable. Of approximately 350 base pairs (bp) sequenced, 52 variable sites, comprising 56 base substitutions, were found among 233 individuals. Offspring populations showed less genetic variability than the parent population in terms of numbers of microsatellite alleles and mtDNA haplotypes, as well as mtDNA haplotype diversity. Statistical analysis of the fixation index $\left(\Phi_{\mathrm{ST}}\right.$ and $\left.F_{\mathrm{ST}}\right)$ and analysis of molecular variance using both DNA markers showed significant genetic differences between the parent and offspring populations. These results suggest that random genetic
\end{abstract}


drift and/or inbreeding events, as well as artificial selection and founder effects, occurred when the offspring strain was reproduced in a hatchery facility despite thousands of males and females from different hatcheries being maintained for artificial reproduction. Therefore, it is necessary to improve current hatchery programs by monitoring genetic variation in both the broodstock and progeny and controlling inbreeding within stocks in commercial breeding facilities to maintain the production of high-quality black rockfish. This information will be useful for determining suitable guidelines for establishing and maintaining cultured stocks and the aquaculture industry of $S$. inermis.

Key words: Black rockfish; Sebastes inermis; Artificial reproduction; Genetic variability; Mitochondrial DNA; Microsatellite loci

\section{INTRODUCTION}

The Korean black rockfish, Sebastes inermis, inhabits shallow rocky shores along the southern coast of Korea, all of Japan, and some parts of China at depths of 10 to 100 $\mathrm{m}$. This species is a major component of the nearshore commercial and recreational fishery resource in Korea, and it has long been considered a common fishery resource along the southern coast of Korea. However, annual catches have declined drastically since the late 1990s. These declines have resulted in increased scientific, economic, and social concerns about the status of the resource and the viability of black rockfish fisheries in Korea. Consequently, interest has been directed towards the possibility of aquaculture, or supplementing natural populations, and advances in artificial propagation techniques in hatcheries have been achieved since 2000 .

Black rockfish farming is a key part of the aquaculture industry in southern Korea. Black rockfish seed are produced exclusively in hatcheries in this region. These hatcheries are of a medium size, and the majority of black rockfish are cultured using the net cage system. Typically, hundreds of potbellied females from cages holding thousands of black rockfish are used in artificial reproduction. Although both wild-caught and captive-cultured broodstock sources are used for artificial reproduction in hatchery stocks, breeding has continued for multiple generations with little introduction of exotic broodstocks because of the difficulty of collecting large numbers of sexually mature wild $S$. inermis. Thus, there are concerns that genetic variability in hatchery stocks might have been lost during artificial propagation. Genetic diversity has been associated with adaptation to new environments, and reduced genetic diversity may have harmful effects on commercially important traits, which can harm the aquaculture industry (Allendorf and Ryman, 1987). Therefore, careless breeding programs may cause decreased genetic diversity of the broodstock (Noguchi and Taniguchi, 2007). The genetic diversity of artificially produced seed is generally lower than that of wild populations because of unconscious selection and the limited number of parents that are used to produce subsequent generations in a hatchery (Kohlmann et al., 2005; Lundrigan et al., 2005; An et al., 2013). Genetic diversity and population structures of wild and cultivated $S$. inermis stocks were recently reported by An et al. $(2011 \mathrm{a}, \mathrm{b})$. There is a need for more research into standard breeding 
practices in hatcheries to maintain cultivated stocks, conserve diversity, and minimize inbreeding to safeguard the future of aquaculture. However, there has been little effort to understand the genetic divergence between parent and offspring populations of the Korean black rockfish produced in hatchery facilities despite concerted efforts aimed at artificial propagation. At this early stage, guidelines based on genetic criteria are essential to found and maintain cultivated stocks and for the production of high-quality black rockfish through aquaculture.

Molecular markers have proven to be excellent indicators of genetic variation within and between populations for many fishery animals (Kitanish et al., 2007; An et al., 2011a,b; Yoon et al., 2011; Choi and Kim, 2012; Han et al., 2012; Hong et al., 2012; Lee and Hur, 2012). Microsatellite DNA markers, in particular, have relatively high levels of polymorphism. Mitochondrial DNA (mtDNA) also has several useful properties that make it a good tool for genetic diversity studies (Loftis et al., 2009). The control region has proven to be a particularly useful genetic marker because of its rapidly evolving locus (due to a non-coding region for a functional gene) coupled with its maternal inheritance (Grunwald et al., 2002). Direct comparisons between mtDNA and microsatellite loci can be very informative, as evolutionary forces will affect each class of marker differently (Hoarau et al., 2004). More recently, mtDNA and microsatellite analyses have been used as powerful tools for estimating population genetic diversity in fish (Blanco et al., 2013).

In this study, we investigated the genetic diversity of parents and their offspring populations of Korean black rockfish to determine whether current standard practices of artificial reproduction in a hatchery facility lead to reduced genetic variation.

\section{MATERIAL AND METHODS}

\section{Fish samples and DNA extraction}

For the genetic diversity analysis, a total of 233 S. inermis individuals were collected from a medium-sized cage at an aquaculture farm in Tongyeong, Korea. Despite the broodstock population in the hatchery facility being reared on an ongoing basis, records and details of their origins were not available. In 2008, artificial seed production using 98 potbellied females from cages holding thousands of black rockfish was carried out in a cylindrical indoor tank because black rockfish are live-bearers, and their offspring were cultured in three tanks. A total of 98 female parents and 38, 47, and 50 offspring were sampled from the three tanks.

Fin or whole-body clips (approximately $1 \mathrm{~cm}^{3}$ ) from parents and offspring were sampled and preserved in $99.9 \%$ ethanol before being transported to the laboratory. Total DNA was extracted using a MagExtractor-Genomic DNA Purification Kit (Toyobo, Japan) according to the manufacturer protocol for the MagExtractor MFX-2100 (Toyobo) automated DNA extraction system. Extracted genomic DNA was stored at $-20^{\circ} \mathrm{C}$ until needed.

\section{mtDNA and microsatellite analyses}

Approximately 350 base pairs (bp) of the non-coding mtDNA control region was amplified via polymerase chain reaction (PCR) using the following primers: D-RF: 
CCTGAAAATAGGAACCAAATGCCAG and Thr-RF: GAGGAYAAAGCACTTGAATGAGC (Hyde and Vetter, 2007). PCRs were carried out in a $50-\mu \mathrm{L}$ volume. Each reaction contained $5 \mu \mathrm{L}$ 10X EX TaqTM buffer (TaKaRa Biomedical Inc., Shiga, Japan), $0.2 \mathrm{mM}$ dNTPs, $0.4 \mu \mathrm{M}$ each primer, $1.25 \mathrm{U}$ EX TaqTM polymerase (TaKaRa Biomedical Inc.), and $5 \mu \mathrm{L}$ genomic DNA. PCR amplification was conducted using an RTC 200 machine (MJ-Research, Watertown, MA, USA). The partial mtDNA control region DNA was amplified under the following conditions: denaturation for $5 \mathrm{~min}$ at $95^{\circ} \mathrm{C}$ followed by 30 cycles of denaturing at $95^{\circ} \mathrm{C}$ for $1 \mathrm{~min}$, annealing at $60^{\circ} \mathrm{C}$ for 1 $\mathrm{min}$, and extension at $72^{\circ} \mathrm{C}$ for $1 \mathrm{~min}$, and a final extension at $72^{\circ} \mathrm{C}$ for $5 \mathrm{~min}$.

The sizes of amplification products were checked by loading $5 \mu \mathrm{L}$ PCR product onto a $2 \%$ agarose gel containing $0.5 \mu \mathrm{L} / \mathrm{mL}$ ethidium bromide. The product was purified using a QIA quick PCR purification kit (Qiagen, Hilden, Germany). Purified product was labeled using the BigDye Terminator 3.1 Cycle sequencing kit (Applied Biosystems, Foster City, CA, USA) and sequenced directly using an ABI3100 Prism automatic DNA sequencer following manufacturer instructions. Direct sequencing of the PCR products was performed on all samples. The primers used for sequencing were the same as those used in the PCR. All final sequences were determined from both strands for verification.

Ten Sebastes schlegeli microsatellite loci (KSs2A, KSs3, KSs5, KSs6, KSs8, KSs11B, KSs16, KSs18A, KSs20A, and KSs27A; GenBank accession numbers EF109802-7, EF109809, EF109811, EF109813, and EF109815) were analyzed (An et al., 2009). The 5' end of the forward primer of each set of primers was labeled with a fluorescent dye (6-FAM, HEX, or NED; Applied Biosystems). PCR amplification of the 10 microsatellite loci was carried out in a $10-\mu \mathrm{L}$ volume containing $0.25 \mathrm{U}$ Taq DNA polymerase, $10 \mathrm{X}$ ExTaq buffer, $2 \mathrm{mM}$ dNTP mixture (Takara), $2 \mu \mathrm{M}$ of each primer set, and about 10-50 ng template DNA using a PTC0220 DNA Engine Dyad Peltier thermal cycler (MJ Research). PCR conditions were as follows: denaturation at $95^{\circ} \mathrm{C}$ for $11 \mathrm{~min}, 35$ cycles of denaturation at $94^{\circ} \mathrm{C}$ for $1 \mathrm{~min}$, annealing at each primer temperature listed in An et al. (2009) for $1 \mathrm{~min}$, and extension at $72^{\circ} \mathrm{C}$ for $1 \mathrm{~min}$, and a final extension at $72^{\circ} \mathrm{C}$ for $5 \mathrm{~min}$.

For genotyping, $1 \mu \mathrm{L}$ PCR product was added to $9 \mu \mathrm{L}$ reaction mixture containing formamide (Hi-Di Formamide, Applied Biosystems) and GeneScan ${ }^{\circledR}$ 400HD (ROX) size standard (ABI PRISM, Applied Biosystems), denatured at $95^{\circ} \mathrm{C}$ for $2 \mathrm{~min}$, and immediately chilled on ice. Fragment analysis of the reaction product was carried out using an ABI 3130 Genetic Analyzer (Applied Biosystems) and the GENEMAPPER software (version 4.0; Applied Biosystems).

\section{Data analysis}

The sequences of the mtDNA control region for the 233 individuals that were sampled were aligned. Multiple sequence alignments were conducted using BioEdit 7.0.1 (Hall, 1999). Gaps were considered to be missing data. The number of variable sites, haplotype frequency distributions, and haplotype diversity were calculated using ARLEQUIN 3.0 (Excoffier et al., 2007). Haplotype diversity was based on the following formula: $\mathrm{h}=\left(1-\sum \mathrm{x}_{i}^{2}\right) n /(n-1)$, where $x_{i}$ is the frequency of a haplotype and $n$ is the sample size (Nei and Tajima, 1981). The genetic distance between populations was determined by the Kimura two-parameter method (Kimura, 1980) and using molecular evolutionary genetic analysis (MEGA 3.1; Kumar et al., 2008). 
Microsatellite allelic loci were scored using GeneMapper version 4.0 (Applied Biosystems) along with a size standard, using an internal control for allele calling, and coded according to size in nucleotides (bp). A panel that included all alleles that were detected in the 233 individuals was created for each locus. We tested for the possible presence of null alleles and genotyping errors caused by stuttering and/or large-allele dropout using MICRO-CHECKER (ver. 2.2.3; 1000 randomizations; van Oosterhout et al., 2004). Scoring and human error were reduced by performing duplicate analyses. As genetic diversity parameters, the number of alleles per locus $\left(N_{\mathrm{A}}\right)$ and number of unique alleles (U), as well as observed and expected heterozygosity values $\left(H_{\mathrm{E}}\right.$ and $H_{\mathrm{O}}$, respectively; Nei, 1987) per locus and sample population were calculated using FSTAT (version 2.9.3.2; Goudet, 1995). FSTAT was also used to ascertain allelic richness $\left(A_{R}\right)$, and differences in sample size were corrected using the rarefaction method. $A_{R}$ can be compared directly between populations regardless of sample size (El Mousadik and Petit, 1996). Differences in genetic diversity parameters were tested using nonparametric analyses (Wilcoxon signed-rank test; Wilcoxon, 1945). Deviations from Hardy-Weinberg equilibrium (HWE) at each locus were tested using a test analogous to the Fisher exact test using the Markov-chain procedure within ARLEQUIN (the Markov-chain parameters were the following: steps, 100,000; dememorization, 10,000). An inbreeding coefficient $\left(F_{\text {IS }}\right.$; Weir and Cockerham, 1984) was also estimated to measure the HWE departures, evaluating the probabilities through random permutation procedures (minimum 10,000 permutations). Significance levels associated with the HWE analysis were adjusted in multiple tests using the sequential Bonferroni correction technique (Rice, 1989). The genetic distance between populations was estimated based on the chord distance, $D_{\mathrm{CE}}$ (Cavalli-Sforza and Edwards, 1967).

To measure levels of population differentiation, overall $F$-statistics (Weir and Cockerham, 1984) were estimated based on mtDNA sequences $\left(\Phi_{\mathrm{ST}}\right)$ and microsatellites $\left(F_{\mathrm{ST}}\right)$ using ARLEQUIN 3.0. The $\Phi_{\mathrm{ST}}$ value for the mtDNA sequence data was calculated by taking different substitution rates between transitions and transversions into account in the Kimura two-parameter method (Kimura, 1980). The probability associated with the $F_{\mathrm{ST}}\left(\Phi_{\mathrm{ST}}\right)$ values was evaluated through random permutation procedures (minimum 10,000 permutations). These results were corroborated by calculating the analysis of molecular variance (AMOVA; Excoffier et al., 1992) and the components of variance within and between populations based on the infinite allele model (IAM) using ARLEQUIN 3.0. The significance of the AMOVA components was tested using 1000 permutations.

\section{RESULTS}

\section{Mitochondrial variability}

Approximately 350-bp sequences containing the left domain of the mtDNA control region were unambiguously determined for a total of 233 individuals from one parent and three offspring populations. There were 52 variable sites consisting of 56 base substitutions (51 transitions and 5 transversions). Consequently, a total of 50 haplotypes were identified in the 233 individuals. Haplotype variabilities of parent and offspring samples are summarized in Tables 1 and 2. Fewer haplotypes were identified in the offspring samples (13-18 haplotypes in 
each of the three stocks) than in the parent population (50 haplotypes). A total of 28 haplotypes were found only in the parent population. Offspring samples in the three tanks showed similar haplotype distributions and frequencies, and they shared common haplotypes. Haplotype and nucleotide diversity were higher in the parent population $(h=0.9638 ; \pi=0.0120)$ than in the offspring samples $(h=0.9159 ; \pi=0.0092)$.

\begin{tabular}{|c|c|c|c|c|c|}
\hline & \multicolumn{4}{|c|}{ Offsprings } & \multirow[t]{2}{*}{ Parents } \\
\hline & Offspring 1 & Offspring 2 & Offspring 3 & Total offsprings & \\
\hline Sample size & 38 & 47 & 50 & 135 & 98 \\
\hline No. of variable sites & 19 & 15 & 26 & 28 & 52 \\
\hline No. of substitutions ${ }^{\mathrm{a}}$ & $\begin{array}{c}19 \\
\text { (Ts: } 17 ; \mathrm{Tv}: 2)\end{array}$ & $\begin{array}{c}15 \\
(\mathrm{Ts}: 12 ; \mathrm{Tv}: 3)\end{array}$ & $\begin{array}{c}26 \\
(\mathrm{Ts}: 24 ; \mathrm{Tv}: 2)\end{array}$ & $\begin{array}{c}29 \\
\text { (Ts:26; Tv:3) }\end{array}$ & $\begin{array}{c}56 \\
\text { (Ts: } 51 ; \mathrm{Tv}: 5 \text { ) }\end{array}$ \\
\hline No. of haplotypes & 16 & 13 & 18 & 22 & 50 \\
\hline Nucleotide diversity $(\pi)$ & $\begin{array}{c}0.010124 \\
( \pm 0.005850)\end{array}$ & $\begin{array}{c}0.008146 \\
( \pm 0.004848)\end{array}$ & $\begin{array}{c}0.009558 \\
( \pm 0.005534)\end{array}$ & $\begin{array}{c}0.011961 \\
( \pm 0.006640)\end{array}$ & $\begin{array}{c}0.009216 \\
( \pm 0.005298)\end{array}$ \\
\hline Haplotype diversity $(h)^{\mathrm{b}}$ & $\begin{array}{c}0.9417 \\
( \pm 0.0090)\end{array}$ & $\begin{array}{c}0.8871 \\
( \pm 0.0156)\end{array}$ & $\begin{array}{c}0.9176 \\
( \pm 0.0233)\end{array}$ & $\begin{array}{c}0.9159 \\
( \pm 0.0095)\end{array}$ & $\begin{array}{c}0.9638 \\
( \pm 0.0204)\end{array}$ \\
\hline
\end{tabular}

\section{Microsatellite variability}

MICRO-CHECKER analysis revealed that four of the 10 loci (KSs2A, KSs3, KSs11B, and KSs18A) were affected by null alleles. However, these loci were included in this study because no null alleles affected all of the populations, and we found no indications of allele scoring errors caused by stuttering or large allele dropout.

All 10 loci were polymorphic, and a total of 134 different alleles were observed across all loci for all samples (Table 3). No single population had a diagnostic allele. The average number of alleles per locus was 11.55, ranging from 6 at KSs 8 to 21.5 at KSs2A. The mean number of alleles was 12.6 in parent population samples, 8.2-8.9 in offspring samples of each tank, and 10.5 in the total offspring samples. In addition, the mean allelic richness was 12.6 in the parent population and 10.06 in the offspring samples. In total, 37 alleles were found to be unique to a single population (Table 3), among which 29 occurred in the parent population and eight were found in the offspring samples. The mean of expected and observed heterozygosity values estimated for the parent population were 0.734 and 0.636 , respectively. This was slightly higher than those of the estimated genotype data of the offspring samples, which were 0.677 and 0.631 . The inbreeding coefficient $\left(F_{\text {IS }}\right)$ value of the offspring samples (0.068) was lower than that of the parent population $(0.134, \mathrm{P}>0.05)$ (Table 3). These results suggest that genetic diversity was lower in the offspring samples. However, despite these differences in genetic diversity, no statistically significant reduction in genetic variability was found in the offspring samples compared to the parent population (Wilcoxon test, $\mathrm{P}>0.05$ ).

Statistically significant deviation from HWE was observed in both parent and offspring populations after adjusting the $\mathrm{P}$ values using the sequential Bonferroni method $(\mathrm{P}<$ 0.005), and these disequilibriums (DHWE) were due to an excess of homozygotes (Table 3). Significant deviations were neither evenly distributed among samples or loci nor associated with a particular locus or sample. Four deviations from equilibrium were observed in the parent population, but five cases were found in the offspring samples. 


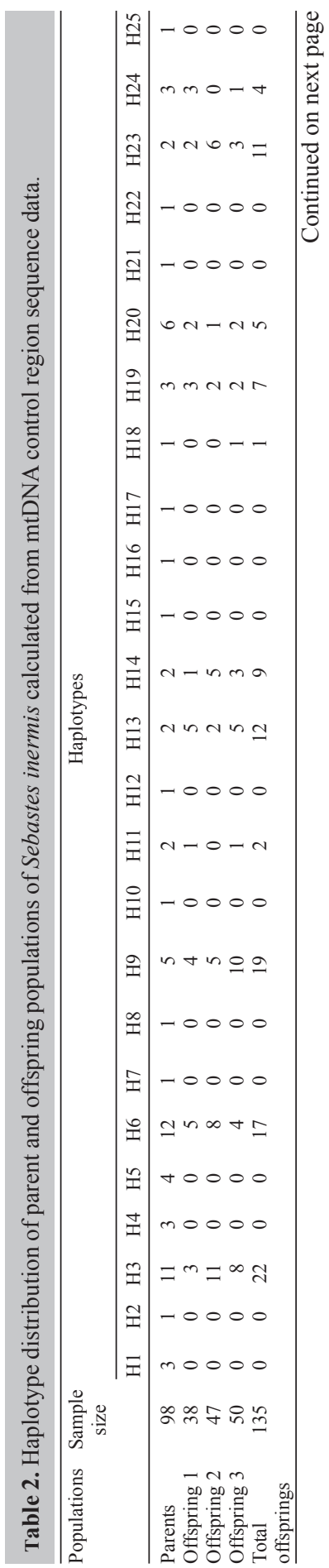




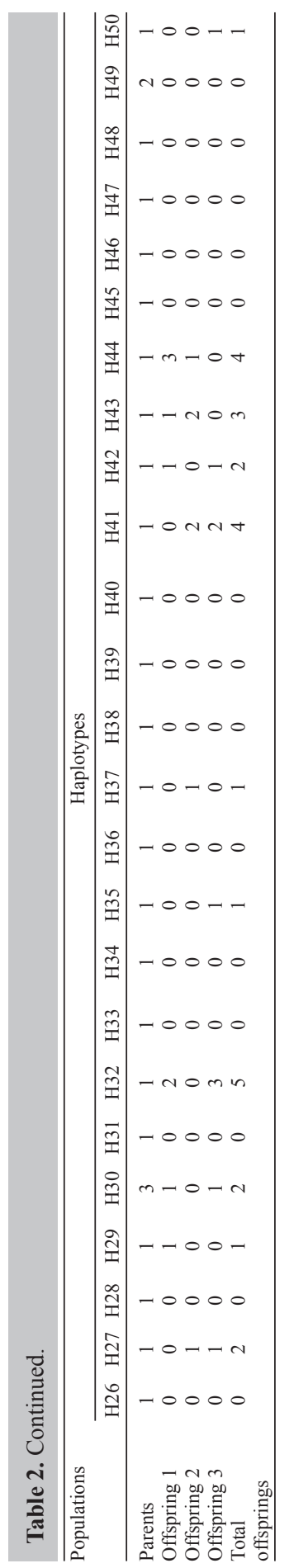




\begin{tabular}{|c|c|c|c|c|c|c|c|c|c|c|c|c|}
\hline \multirow[t]{2}{*}{ Population (No.) } & & \multicolumn{11}{|c|}{ Microsatellite loci } \\
\hline & & KSS2A & KSS3 & KSS5 & KSS6 & KSS8 & KSS11B & KSS16 & KSS18A & KSS20A & KSS27A & Mean \\
\hline \multirow[t]{7}{*}{ Parents (98) } & $N_{\mathrm{A}}$ & 24 & 15 & 7 & 18 & 7 & 7 & 10 & 10 & 10 & 18 & 12.60 \\
\hline & $A_{R}^{A}$ & 24.00 & 15.00 & 7.00 & 18.00 & 7.00 & 7.00 & 10.00 & 10.00 & 10.00 & 18.00 & 12.60 \\
\hline & $\mathrm{S}^{\mathrm{K}}$ & $132-196$ & $136-180$ & $124-136$ & $136-174$ & $160-178$ & $116-130$ & $104-122$ & $224-250$ & $230-264$ & $186-252$ & \\
\hline & $\mathrm{U}$ & 6 & 3 & 1 & 2 & 2 & 1 & 3 & 3 & 3 & 5 & 2.90 \\
\hline & $H_{\mathrm{E}}$ & 0.833 & 0.888 & 0.466 & 0.883 & 0.670 & 0.716 & 0.742 & 0.823 & 0.707 & 0.608 & 0.734 \\
\hline & $H_{\mathrm{O}}^{\mathrm{E}}$ & 0.776 & 0.714 & 0.337 & 0.827 & 0.704 & 0.633 & 0.704 & 0.643 & 0.439 & 0.582 & 0.636 \\
\hline & $F_{\text {IS }}^{0}$ & $0.069^{*}$ & $0.196^{*}$ & $0.279 *$ & 0.064 & -0.051 & 0.117 & 0.051 & 0.220 & $0.381^{*}$ & 0.044 & 0.134 \\
\hline \multirow[t]{5}{*}{ Offspring 1 (38) } & $N_{\mathrm{A}}^{\mathrm{IS}}$ & 14 & 11 & 6 & 15 & 5 & 7 & 6 & 7 & 7 & 11 & 8.90 \\
\hline & $\mathrm{S}^{\mathrm{A}}$ & $136-194$ & $142-166$ & $124-138$ & $144-178$ & $164-178$ & $120-132$ & $110-122$ & $236-250$ & $248-264$ & $202-230$ & \\
\hline & $H_{\mathrm{E}}$ & 0.731 & 0.852 & 0.491 & 0.871 & 0.581 & 0.615 & 0.636 & 0.790 & 0.760 & 0.536 & 0.686 \\
\hline & $H_{\mathrm{O}}$ & 0.605 & 0.868 & 0.553 & 0.816 & 0.526 & 0.658 & 0.658 & 0.579 & 0.737 & 0.395 & 0.640 \\
\hline & $F_{\text {IS }}^{0}$ & $0.173^{*}$ & -0.019 & -0.127 & 0.064 & 0.095 & -0.071 & -0.034 & $0.270 *$ & 0.031 & 0.267 & 0.069 \\
\hline \multirow[t]{5}{*}{ Offspring 2 (47) } & $N_{\mathrm{A}}^{1 \mathrm{~s}}$ & 12 & 10 & 6 & 17 & 4 & 7 & 7 & 7 & 6 & 13 & 8.90 \\
\hline & $\mathrm{S}^{\mathrm{A}}$ & $132-170$ & $148-178$ & $124-136$ & $136-178$ & $164-176$ & $120-132$ & $110-122$ & $236-250$ & $248-258$ & $200-252$ & \\
\hline & $H_{\mathrm{E}}$ & 0.717 & 0.831 & 0.308 & 0.880 & 0.535 & 0.662 & 0.664 & 0.735 & 0.686 & 0.707 & 0.673 \\
\hline & $H_{\mathrm{O}}^{\mathrm{E}}$ & 0.660 & 0.723 & 0.298 & 0.894 & 0.489 & 0.681 & 0.660 & 0.553 & 0.681 & 0.617 & 0.626 \\
\hline & $F_{\mathrm{IS}}^{0}$ & $0.081^{*}$ & 0.130 & 0.032 & -0.016 & 0.086 & -0.029 & 0.007 & 0.249 & 0.007 & 0.129 & 0.070 \\
\hline Offspring 3 & $N_{\mathrm{A}}$ & 11 & 11 & 7 & 15 & 4 & 5 & 6 & 7 & 6 & 10 & 8.20 \\
\hline \multirow[t]{4}{*}{ (50) } & $\mathrm{S}^{\mathrm{A}}$ & $136-196$ & $148-178$ & $124-138$ & $136-178$ & $164-178$ & $120-128$ & $110-120$ & $236-250$ & $248-258$ & $200-252$ & \\
\hline & $H_{\mathrm{E}}$ & 0.716 & 0.856 & 0.427 & 0.869 & 0.588 & 0.619 & 0.632 & 0.701 & 0.613 & 0.636 & 0.666 \\
\hline & $H_{\mathrm{O}}$ & 0.640 & 0.820 & 0.420 & 0.820 & 0.640 & 0.580 & 0.580 & 0.740 & 0.540 & 0.520 & 0.630 \\
\hline & $F_{\text {IS }}$ & 0.107 & 0.043 & 0.016 & 0.057 & -0.089 & $0.064 *$ & 0.083 & -0.056 & 0.120 & 0.184 & 0.054 \\
\hline Total Offsprings & $N_{\mathrm{A}}^{\mathrm{IS}}$ & 19 & 12 & 7 & 18 & 5 & 7 & 7 & 7 & 7 & 16 & 10.50 \\
\hline \multirow[t]{6}{*}{ (135) } & $A_{R}^{A}$ & 16.85 & 11.65 & 6.85 & 17.74 & 4.93 & 6.98 & 6.98 & 7.00 & 6.93 & 14.67 & 10.06 \\
\hline & $\mathrm{S}^{\mathrm{K}}$ & $132-196$ & $142-178$ & $124-138$ & $136-178$ & $164-178$ & $120-132$ & $110-122$ & $236-250$ & $248-264$ & $200-252$ & \\
\hline & $\mathrm{U}$ & 1 & 0 & 1 & 2 & 0 & 1 & 0 & 0 & 0 & 3 & 0.800 \\
\hline & $H_{\mathrm{E}}$ & 0.718 & 0.845 & 0.405 & 0.878 & 0.566 & 0.637 & 0.645 & 0.755 & 0.686 & 0.634 & 0.677 \\
\hline & $H_{\mathrm{O}}^{\mathrm{E}}$ & 0.637 & 0.800 & 0.415 & 0.844 & 0.556 & 0.637 & 0.630 & 0.630 & 0.644 & 0.519 & 0.631 \\
\hline & $F_{\mathrm{IS}}$ & $0.113^{*}$ & $0.054 *$ & -0.024 & $0.038^{*}$ & 0.018 & -0.001 & $0.024 *$ & $0.167 *$ & 0.061 & 0.183 & 0.068 \\
\hline \multirow{5}{*}{$\begin{array}{l}\text { Mean of parent } \\
\text { and offspring } \\
\text { populations }\end{array}$} & $F_{S T}^{1 \mathrm{~S}}$ & 0.011 & 0.004 & 0.002 & 0.009 & 0.009 & 0.009 & 0.006 & 0.028 & 0.019 & 0.003 & 0.011 \\
\hline & $N_{\mathrm{A}}^{S \mathrm{~T}}$ & 21.50 & 13.50 & 7.00 & 18.00 & 6.00 & 7.00 & 8.50 & 8.50 & 8.50 & 17.00 & 11.55 \\
\hline & $A_{R}^{A}$ & 20.43 & 13.32 & 6.93 & 17.87 & 5.96 & 6.99 & 8.49 & 8.50 & 8.46 & 16.34 & 11.33 \\
\hline & $H_{\mathrm{E}}^{\mathrm{R}}$ & 0.776 & 0.867 & 0.436 & 0.881 & 0.618 & 0.677 & 0.694 & 0.789 & 0.697 & 0.621 & 0.705 \\
\hline & $H_{\mathrm{O}}^{\mathrm{E}}$ & 0.707 & 0.757 & 0.376 & 0.836 & 0.630 & 0.635 & 0.667 & 0.637 & 0.542 & 0.551 & 0.634 \\
\hline
\end{tabular}

\section{Genetic differentiation between populations}

$\Phi_{\mathrm{ST}}$ and $F_{\mathrm{ST}}$ estimates between parent and offspring populations using both mtDNA and microsatellites are shown in Table 4. There was significant heterogeneity in the distribution of allele frequencies $(\mathrm{P}<0.001)$ between the two populations, confirming their genetic divergence. There were no significant differences observed using both DNA markers in the offspring samples in all three tanks, suggesting a common gene pool. AMOVA analysis did reveal a small but significant genetic differentiation between parent and offspring populations in both DNA markers $(\mathrm{P}<0.001)$.

Table 4. $\Phi_{\mathrm{ST}}$ of mtDNA (below the diagonal) and $F_{\mathrm{ST}}\left(D_{\mathrm{CE}}\right)$ of microsatellite estimates (above the diagonal) between parent and offspring populations of Sebastes inermis.

\begin{tabular}{lcc}
\hline & Parents & Offsprings \\
\hline Parents & - & $0.0114 *(0.18495)$ \\
Offsprings & $0.0268^{*}(0.01102)$ & - \\
\hline
\end{tabular}

Probability of differentiation with P value was calculated from 1000 replications. 


\section{DISCUSSION}

Genetic variability is the primary biological resource in the successful artificial propagation of any species (Allendorf and Phelps, 1980). Because of an important high additive genetic variance for productive traits, maintaining genetic variation is believed to be essential for the long-term survival of populations; this is especially true for species that are domesticated or artificially farmed (Alarcón et al., 2004). In aquaculture, there are major concerns about the loss of genetic variability in offspring during hatchery production. In this study, the results from analyses of two genetic markers (the mtDNA control region and microsatellites) indicated that levels of genetic variability are lower in offspring than in the parent population (Tables 1-3). There was a dramatic decline in the number of haplotypes of mitochondrial D-loop sequences. mtDNA variability is expected to be highly susceptible to stochastic events because the mitochondrial genome is transmitted through a single maternal line that does not undergo recombination (Carvalho and Hauser, 1994). The fact that the offspring mtDNA markers contained haplotypes that were observed in the parent population implies that the offspring came from effective female parents. Microsatellite genotyping detected the loss of many rare alleles. Although allelic diversity in terms of the number of alleles per locus has been shown to be variable depending on the sample size, the sample size of offspring in this study was larger than that of the parent population. We found that genetic diversity was similar in $S$. inermis, but the number of alleles per locus was relatively higher than that reported by An et al. (2011a). Because allele number is positively correlated with sample size (Liu et al., 2009), the number of alleles observed in this study was probably due to the relatively large sample size. Overall heterozygosity associated with the microsatellite loci did not show pronounced differences between the populations examined. These results are hardly surprising because the loss of low-frequency alleles seems to have little effect on heterozygosity (Allendorf, 1986). Regarding the microsatellite marker data, the fact that the offspring samples contained unique alleles implies that effective male parents (not analyzed in this study) have contributed unique alleles to offspring. Despite the standard practice of using thousands of males and females from different hatcheries in hatcheries producing Korean black rockfish, the decline in genetic variation of the offspring stock could be caused by founder effects, artificial selection, inbreeding, and/or the increased effects of genetic drift. Effective population size in captive populations is affected by several factors such as the number of contributing broodstock to the next generation, sex ratio of parents, and variations in family size (Sekino et al., 2003).

The preservation of genetic variation is an important consideration in maintaining any hatchery stock to provide fish to maintain wild populations or to serve as a representative source of genetic variation. In hatchery strains, it is generally recommended that unrelated fish from the wild should be used as broodstock because they can produce offspring that have a higher fitness in the wild than offspring from older, domesticated hatchery stocks, even though first-generation hatchery fish still have reduced fitness in the wild (Theriault et al., 2011; Christie et al., 2012). However, this is often difficult to do because of economic constraints. Instead, a subset of hatchery-based fish is normally used to comprise the broodstock. Historically, hatchery managers preferred to use fish born in hatcheries as broodstock to create future generations because whatever trait they had that allowed them to succeed in the hatchery helped produce thousands of apparently healthy young offspring. However, this practice can have unintentional negative effects on the genetic variability of the broodstock (Allendorf 
and Ryman, 1987) even though the hatcheries use thousands of males and females from different hatcheries. It is important to periodically introduce new genetic material from local wild stocks. This infusion would preserve the black rockfish gene pool and would enable hatchery production of fish that could perform well when returned to the wild. In addition, reproduction procedures should be designed to minimize the loss of genetic variation. Maximal retention of genetic variability can be achieved through monitoring the pedigree structure of descendants and suitably selecting reproducers among unrelated descendants (Norris et al., 2000).

A significant deficit of heterozygotes and deviation from HWE were detected in both the parent and offspring populations. A similar phenomenon was also observed in a previous microsatellite analysis (An et al., 2011a). It is possible that null or non-amplifying alleles could account for the heterozygote deficiencies in the data. The presence of null alleles has also been reported for numerous other fishery animals (Frankham et al., 2002; Keller and Waller, 2002). An increased occurrence of DHWE in the offspring stock could have resulted from inbreeding and/or natural selection during artificial production.

Genetic differentiation detected by $\Phi_{\mathrm{ST}}$ and $F_{\mathrm{ST}}$ estimates between parent and offspring populations gave similar results. There were significant genetic differences between parent and offspring populations. This genetic divergence may be caused by artificial selection, founder effects, and/or random genetic drift in the offspring stock or in the breeding program. However, artificial selection and founder effects should only have a minor effect on differentiation because a large number of potbellied females from cages holding thousands of black rockfish were used for artificial reproduction. On the other hand, the effect of random genetic drift could be an important reason for the significant differentiation. The random genetic drift may be caused by an unequal sex ratio or by the differential reproductive contribution of the brooders in the hatchery (Liu et al., 2009).

In conclusion, this study demonstrated that genetic changes, including reduced genetic diversity and significant differentiation, have occurred in offspring stock of $S$. inermis compared to the parent population because of artificial selection, founder effects, inbreeding, and random genetic drift caused by the aquaculture practices in a hatchery. This result provides important information for ongoing breeding programs. Additional monitoring of genetic variability in broodstock and progeny and continuous control of inbreeding in commercial breeding practices are required to improve the sustainable genetic management of hatchery stocks. This information can be used to design suitable management guidelines for this fish stock or for other related species.

\section{ACKNOWLEDGMENTS}

Research supported by a grant from the Korean National Fisheries Research and Development Institute (NFRDI), contribution number \#RP-2013-BT-078. The views expressed here are those of the authors and do not necessarily reflect the views of NFRDI.

\section{REFERENCES}

Alarcón JA, Magoulas A, Georgakopoulos, Zouros T, et al. (2004). Genetic comparison of wild and cultivated European populations of the gilthead sea bream (Sparus aurata). Aquaculture 230: 65-80.

Allendorf FW (1986). Genetic drift and the loss of alleles versus heterozygosity. Zoo. Biol. 5: 181-190.

Allendorf FW and Phelps SR (1980). Loss of genetic variation in a hatchery stock of cutthroat trout. Trans. Am. Fish.

Genetics and Molecular Research 12 (4): 6389-6401 (2013)

CFUNPEC-RP www.funpecrp.com.br 
Soc. 109: 537-543.

Allendorf FW and Ryman N (1987). Genetic Management of Hatchery Stocks. (Ryman N and Utter F, eds.). Population Genetics and Fishery Management, Washington Sea Grant. University of Washington Press, Seattle, 141-159.

An HS, Hong SW, Kim EM and Myeong JI (2011a). Comparative genetic diversity of wild and hatchery populations of Korean threadsail filefish Stephanolepis cirrhifer using cross-species microsatellite markers. Genes Genomics 33: 605-611.

An HY, Park JY, Kim MJ, Lee EY, et al. (2009). Isolation and characterization of microsatellite markers for the heavily exploited rockfish Sebastes schlegeli, and cross-species amplification in four related Sebastes spp. Conserv. Genet. 10: 1969-1972.

An HS, Kim EM, Lee JH, Noh JK, et al. (2011b). Population genetic structure of wild and hatchery black rockfish Sebastes inermis in Korea, assessed using cross-species microsatellite markers. Genet. Mol. Res. 10: 2492-2504.

An HS, Lee JW, Park JY and Jung HT (2013). Genetic structure of the Korean black scraper Thamnaconus modestus inferred from microsatellite marker analysis. Mol. Biol. Rep. 40: 3445-3456.

Blanco GE, Aritaki M, Sakurai S and Taniguchi N (2013). Inference of potential genetic risks associated with large-scale releases of red sea bream in Kanagawa prefecture, Japan based on nuclear and mitochondrial DNA analysis. Mar. Biotechnol. 15: 206-220.

Carvalho GR and Hauser L (1994). Molecular genetics and the stock concept in fisheries. Rev. Fish Biol. Fish. 4: 326-350.

Cavalli-Sforza LL and Edwards AWF (1967). Phylogenetic analysis: models and estimation procedures. Evolution 21: 550-570.

Choi CG and Kim JM (2012). Detection of Laminariaceae species based on PCR by family-specific ITS primers. Fish. Aquat. Sci. 15: 157-162.

Christie MR, Marine ML, French RA and Blouin MS (2012). Genetic adaptation to captivity can occur in a single generation. Proc. Natl. Acad. Sci. U. S. A. 109: 238-242.

El Mousadik A and Petit RJ (1996). High level of genetic differentiation for allelic richness among populations of the argan tree [Argania spinosa (L.) Skeels] endemic to Morocco. Theor. Appl. Genet. 92: 832-839.

Excoffier L, Smouse PE and Quattro JM (1992). Analysis of molecular variance inferred from metric distances among DNA haplotypes: application to human mitochondrial DNA restriction data. Genetics 131: 479-491.

Excoffier L, Laval G and Schneider S (2007). Arlequin (version 3.0): an integrated software package for population genetics data analysis. Evol. Bioinform. Online 1: 47-50.

Frankham R, Ballou J and Briscoe D (2002). Introduction to Conservation Genetics. Cambridge University Press, Cambridge, 640.

Goudet J (1995). FSTAT: a computer program to calculate F-statistics. J. Hered. 86: 485-486.

Grunwald C, Stabile J, Waldman JR, Gross R, et al. (2002). Population genetics of shortnose sturgeon Acipenser brevirostrum based on mitochondrial DNA control region sequences. Mol. Ecol. 11: 1885-1898.

Hall TA (1999). BioEdit: A user-friendly biological sequence alignment editor and analysis program for windows 95/98/ NT. Nucleic Acids Symp. Ser. 41: 95-98.

Han HS, Nam BH, Kang JH, Kim YK, et al. (2012). Genetic variation in wild and cultured populations of the sea squirt Halocynthia roretzi inferred from microsatellite DNA analysis. Fish. Aquat. Sci. 15: 151-155.

Hoarau G, Piquet AMT, Van der Veer HW, Rijnsdorp AD, et al. (2004). Population structure of plaice (Pleuronectes platessa L.) in northern Europe: a comparison of resolving power between microsatellites and mitochondrial DNA data. J. Sea Res. 51: 183-190.

Hong SE, Kim JG, Yu JN, Kim KY, et al. (2012). Genetic variation in the Asian shore crab Hemigrapsus sanguineus in Korean coastal waters as inferred from mitochondrial DNA sequences. Fish. Aquat. Sci. 15: 49-56.

Hyde JR and Vetter RD (2007). The origin, evolution, and diversification of rockfishes of the genus Sebastes (Cuvier). Mol. Phylogenet. Evol. 44: 790-811.

Keller LF and Waller DM (2002). Inbreeding effects in wild populations. Trends Ecol. Evol. 17: 230-241.

Kimura M (1980). A simple method for estimating evolutionary rates of base substitutions through comparative studies of nucleotide sequences. J. Mol. Evol. 16: 111-120.

Kitanish S, Edo K, Yamamoto T, Azuma N, et al. (2007). Genetic structure of masu salmon (Oncorhynchus masou) populations in Hokkaido, northern-most Japan, inferred from mitochondrial DNA variation. J. Fish Biol. 71: 437452.

Kohlmann K, Kersten P and Flajshans M (2005). Microsatellite-based genetic variability and differentiation of domesticated, wild and feral common carp (Cyprinus carpio L.) populations. Aquaculture 247: 253-266.

Kumar S, Nei M, Dudley J and Tamura K (2008). MEGA: a biologist-centric software for evolutionary analysis of DNA and protein sequences. Brief. Bioinformatics 9: 299-306.

Lee HJ and Hur SB (2012). Comparison between phylogenetic relationships based on 18S rDNA sequences and growth 
by salinity of Chlorella-like species (Chlorophyta). Fish. Aquat. Sci. 15: 125-135.

Liu F, Xia JH, Bai ZY and Fu JJ (2009). High genetic diversity and substantial population differentiation in grass carp (Ctenopharyngodon idella) revealed by microsatellite analysis. Aquaculture 297: 51-56.

Loftis DG, Echelle AA, Koike H, van den Bussche RA, et al. (2009). Genetic structure of wild populations of the endangered desert pupfish complex (Cyprinodontidae: Cyprinodon). Conserv. Genet. 10: 453-463.

Lundrigan TA, Reist JD and Ferguson MM (2005). Microsatellite genetic variation within and among Arctic charr (Salvelinus alpinus) from aquaculture and natural populations in North America. Aquaculture 244: 63-75.

Nei M and Tajima F (1981). DNA polymorphism detectable by restriction endonucleases. Genetics 97: 145-163.

Nei M (1987). Molecular Evolutionary Genetics. Columbia University Press, New York.

Norris AT, Bradley DG and Cunnigham EP (2000). Parentage and relatedness determination in farmed Atlantic salmon (Salmo salar) using microsatellite markers. Aquaculture 182: 73-83.

Rice WR (1989). Analyzing tables of statistical tests. Evolution 43: 223-225.

Sekino M, Saitoh K, Yamada T, Kumagai A, et al. (2003). Microsatellite-based pedigree tracing in a Japanese flounder Paralichthys olivaceus hatchery strain: implications for hatchery management related to stock enhancement program. Aquaculture 221: 255-263.

Theriault V, Moyer GR, Jackson LS, Blouin MS, et al. (2011). Reduced reproductive success of hatchery coho salmon in the wild: insights into most likely mechanisms. Mol. Ecol. 20: 1860-1869.

van Oosterhout C, Hutchinson WF, Wills DPM and Shipley P (2004). MICRO-CHECKER: software for identifying and correcting genotyping errors in microsatellite data. Mol. Ecol. Notes 4: 535-538.

Weir BS and Cockerham CC (1984). Estimating F-statistics for the analysis of population structure. Evolution 38: 13581370.

Wilcoxon F (1945). Individual comparisons by ranking methods. Biometrics Bull. 1: 80-83.

Yoon M, Jung JY, Nam YK and Kim DS (2011). Genetic diversity of thread-sail filefish Stephanolepis cirrhifer populations in Korean coastal waters inferred from mitochondrial DNA sequence analysis. Fish. Aquat. Sci. 14: 16-21. 